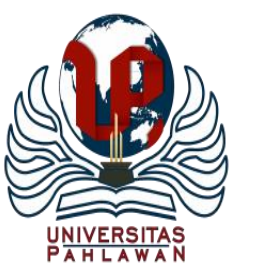

Jurnal Basicedu Volume 4 Nomor 3 Tahun 2020 Halm. 673 - 680

JURNAL BASICEDU

Research \& Learning in Elementary Education

https://jbasic.org/index.php/basicedu/index

\title{
Pengaruh Model Pembelajaran Jigsaw Terhadap Hasil Belajar Bahasa Indonesia Di Sekolah Dasar
}

\author{
Diki Heriwan ${ }^{1}$, Taufina ${ }^{2}$ \\ , Universitas Negeri Padang, Sumatera Barat, Indonesia ${ }^{1,2}$ \\ e-mail: dikiheriwan1@gmail.com ${ }^{1}$, taufina@ fip.unp.ac.id ${ }^{2}$
}

\begin{abstract}
Abstrak
Latar belakang penelitian tentang kegiatan belajar mengajar di kelas yang menjadi pusat perhatian adalah guru, sehingga mempengaruhi hasil belajar siswa. Rendahnya hasil belajar siswa mengharuskan guru untuk meningkatkan proses pembelajaran, salah satu caranya adalah dengan menerapkan model pembelajaran Jigsaw. Penelitian ini bertujuan untuk mengetahui pengaruh pembelajaran Jigsaw terhadap hasil belajar bahasa Indonesia untuk siswa kelas V di SDN 9 Aie Pacah Padang. Penelitian eksperimental ini menggunakan Randomized Control Group Posttest Only Design. Populasi penelitian adalah semua siswa kelas VA dan VB, dengan teknik total sampling. Penentuan kelas eksperimen dan kelas kontrol dilakukan dengan lotere, sehingga kelas VB diperoleh sebagai kelas eksperimen dengan total 20 siswa dan kelas VA sebagai kelas kontrol dengan total 19 siswa. Instrumen penelitian adalah tes hasil belajar siswa yang diperoleh pada akhir kegiatan penelitian. Data dianalisis menggunakan uji-t. Berdasarkan analisis data diperoleh t-hitung $=11,139$ dan $\mathrm{t}$-tabel $=3,808$ yaitu t-hitung $>\mathrm{t}$-tabel maka hipotesis diterima.
\end{abstract}

Kata kunci: pembelajaran Jigsaw, hasil belajar

\begin{abstract}
The background research on teaching and learning activities in the class that is the center of attention is the teacher, so that it affects the student learning outcomes. The low student learning outcomes require teachers to improve the learning process, one of the ways is by implementing a jigsaw learning model. This study aims to determine the effect of jigsaw learning on Indonesian language learning outcomes for fifth grade students at SDN 9 Aie Pacah Padang. This experimental research uses the Randomized Control Group Posttest Only Design. The study population was all students of class VA and VB, with a total sampling technique. Determination of the experimental class and the control class was conducted by lottery, so that the VB class was obtained as an experimental class with a total of 20 students and the VA class as a control class with a total of 19 students. Research instruments are tests of student learning outcomes obtained at the end of research activities. Data were analyzed using $t$-test. Based on the analysis of the data obtained $t_{\text {count }}=11,139$ and $t_{\text {table }}=3,808$ that is $t_{\text {count }}>t_{\text {table }}$ then the hypothesis is accepted.
\end{abstract}

Keywords: Jigsaw lessons, learning outcome

Copyright (c) 2020 Diki Heriwan, Taufina

Corresponding author :

Address : -

Email : :

ISSN 2580-3735 (Media Cetak)

Phone :-

ISSN 2580-1147 (Media Online)

DOI: $10.31004 /$ basicedu.v4i3.416 


\section{PENDAHULUAN}

Perkembangan pendidikan di dunia yang bergerak begitu cepat sangat mempengaruhi kemajuan seuatu negara karena salah satu cara megetahui negara itu maju adalah karena tingginya tingkat pendidikan disuatu negara. Menurut Bessho "Education is everything that is done by the government of a country to reflect the ability of students to excel in their lives." Pendidikan adalah segala cara yang dilakukan oleh pemerintah suatu negara untuk mencerdaskan kemampuan peserta didik agar berprestasi didalam kehidupannya (Bessho et al., 2019). Sedangkan menurut Pane \& Patriana pendidikan adalah suatu langkah dalam memperbaiki karakter seseorang agar bisa menjadi pribadi yang berakhlak mulia, cerdas, dan dapat beradaptasi di lingkungannya (Pane \& Patriana, 2016).

Dari uraian diatas disimpulkan pendidikan itu sangatlah penting dalam rangka untuk menjadi pribadi yang cerdas, berprestasi, dan berkarakter sehingga seseorang dapat diandalkan di lingkungan sekitarnya. Sehubungan dengan itu revolusi industri 4.0 sedang kita jalani dan akan menuju ke tahap revolusi industri selanjutnya, maka seseorang dituntut harus menguasai teknologi dan informasi.

Menurut (Taufina et al., 2019) anak yang tumbuh dan berkembang dengan kemajuan teknologi dengan mudah mengikuti pembelajaran dengan mengintegrasikan teknologi ke dalam pembelajaran tematik di sekolah dasar. Padahal anak yang tumbuh dan berkembang dengan tidak mengikuti kemajuan teknologi mengalami kesulitan dan kecanggungan dalam belajar dengan mengintegrasikan teknologi dalam pembelajaran tematik di sekolah dasar. Integrasi teknologi dalam pembelajaran tematik untuk era Revolusi Industri 4,0 di sekolah dasar di daerah perkotaan dan pedesaan perlu dipertimbangkan untuk meningkatkan kualitas pendidikan di Indonesia.

Menurut (Winarto, 2020) dalam menjalani revolusi 4.0 ini, Kepala Sekolah harus mampu meningkatkan kualitas pendidikan dengan pengembangan diri dan manajemen pendidikan yang baik. Oleh karena itu, masalah yang perlu mendapat perhatian adalah meningkatkan kompetensi pedagogik guru dalam membuat media pembelajaran sehingga mereka siap menghadapi berbagai perubahan di bidang pendidikan. Dari uraian diatas dapat disimpulkan menjalani revolusi industri 4.0 diperlukan sumber daya yang berkualitas. Menurut Madhavi \& Murthy kualiatas adalah mutu sumber daya yang ada yang sangat berharga dan dengan sumber daya tersebut dapat memakmurkan berbagai aspek kehidupan. Misalnya peningkatan mutu pendidikan dengan sumber daya yang berkualitas, penerapan pendidikan berbasis hasil ke dalam kurikulum (Madhavi \& Murthy, 2020). Proses pembelajaran yang berkualitas adalah proses pembelajaran yang berjalan sesuai dengan tujuan-tujuan pembelajaran yang mana pembelajaran efektif, efisien dan optimal (Fahyuni \& Fauji, 2017). Proses pembelajaran merupakan langkah untuk mencapai tujuan pendidikan nasional yang dilaksanakan oleh guru untuk menjadikan siswanya berkarakter positif. (Lubis et al., 2019).

Kedekatan dan taladan guru sangat diutamakan dalam rangka menciptakan suasana 
ceria dan menyenangkan (Taufina, 2016). Sekolah dasar merupakan tempat awal peserta didik melaksanakan pendidikan formal, disinilah peran guru sangat besar dalam pengembangan aspek kognitif, afektif, dan psikomotor peserta didik (Sukma et al., 2019).

Siswa sekolah dasar pada umumnya adalah siswa yang berumur 6-7 sampai dengan 12 tahun, pada masa usia ini anak sangat mudah menyerap ilmu pengetahuan (Pina \& Rubio, 2017). Di sekolah dasar siswa akan mempelajari lima bidang ilmu pokok yang salah satunya adalah Bahasa Indonesia. Menurut (Kichi Hermansyah \& Hasanah, 2017) pembelajaran bahasa Indonesia adalah pembelajaran yang bertujuan untuk mengajarkan bahasa Indonesia dalam hal lisan dan tulisan dalam bentuk keterampilan. Ketermpilan berbahasa Indonesia tersebut adalah keterampilan dalam menjalani kehidupan sehari-hari yang bertujuan menanamkan sikap sosial dan cinta budaya siswa (Muhammadi et al., 2018).

Sesuai dengan kegiatan observasi di SDN 9 Aie Pacah Padang hari Selasa, 10 Oktober 2017 bersama guru kelas VA pada pukul 08.00-10.20 WIB, dan di kelas VB pada hari Senin, 16 Oktober 2017 bersama guru kelas pada pukul 08.00-10.20 WIB di SDN 9 Aie Pacah Padang, dalam pembelajaran Bahasa Indonesia. Diperoleh gambaran bahwa guru jarang menggunakan model pembelajaran, motivasi siswa mengikuti pelajaran masih rendah, siswa kurang aktif mengikuti pelajaran, dan hasil belajar siswa masih rendah.

Berdasarkan hasil wawancara yang dilakukan pada guru kelas VA dan VB SDN 9 Aie Pacah Padang, informasi yang diperoleh bahwa hasil belajar Bahasa Indonesia siswa masih banyak dibawah kriteria ketuntasan minimal (KKM) yang telah ditetapkan di sekolah yaitu 75. Hasil belajar Bahasa Indonesia tersebut dilihat dari hasil ulangan harian III pada ajaran tahun 2017/2018 yang dapat dilihat pada tabel berikut:

Tabel 1. Nilai Ulangan Harian III pada Mata Pelajaran Bahasa Indonesia.

\begin{tabular}{|c|c|c|c|c|c|c|}
\hline Kelas & $\begin{array}{c}\text { Banyak } \\
\text { Siswa }\end{array}$ & KKM & \multicolumn{2}{|c|}{$\begin{array}{c}\text { Siswa Yang } \\
\text { Tuntas }\end{array}$} & \multicolumn{2}{c|}{$\begin{array}{c}\text { Siswa Yang } \\
\text { Tidak Tuntas }\end{array}$} \\
\cline { 4 - 7 } & & & Jumlah & Persen & Jumlah & Persen \\
\hline V A & 19 & 75 & 11 & $58 \%$ & 8 & $42 \%$ \\
\hline V B & 20 & 75 & 11 & $55 \%$ & 9 & $452 \%$ \\
\hline
\end{tabular}

Dapat dilihat pada tabel 1 menunjukkan

bahwa hasil belajar Bahasa Indonesia masih berada pada kategori rendah jika dilihat dari kriteria ketuntasan minimal yang ditetapkan sekolah pada bidang studi Bahasa Indonesia. Disadari dalam hal ini maka salah satu cara mengatasi kondisi ini adalah dengan mengadaptasi model pembelajaran pada bidang studi Bahasa Indonesia. Salah satu model pembelajaran yang peneliti lakukan adalah model pembelajaran koopertif Jigsaw. Model pembelajaran kooperativ Jigsaw ini adalah model pembelajaran yang paling sering digunakan dan sangat cocok pada bidang studi Bahasa Indonesia. Karena pembelajaran Jigsaw adalah model pembelajaran yang dirancang untuk meningkatkan rasa percaya diri dan tanggung jawab siswa terhadap pembelajarannya sendiri dan kelompoknya. Siswa tidak mempelajari materi saja melainkan harus dapat mengatasi masalah proses pembelajaran di dalam kelompoknya. Adapun langkah-langkahnya yaitu sebagai berikut: (1) siswa dibagi menjadi beberapa 
kelompok secara heterogen, (2) beranggotakan 45 orang dengan menggunakan kelompok asal dan kelompok ahli. Disini guru harus kreatif dan aktif supaya dapat mengetahui alur dan latar belakang siswa dalam proses pembelajaran (Putra et al., 2018).

\section{METODE}

Penelitian ini menggunakan metode eksperimen. (Lufri, 2005) menjelaskan jenis penelitian eksperimen adalah penelitian dengan cara pengimplementasian kegiatan di lapangan dengan mengadakan perlakuan terhadap suatu variabel penelitian. Kemudian mengamati pengaruh dari perilaku terhadap variabel yang diteliti tersebut. Rancangan penelitian eksperimen ini adalah dengan cara pengambilan sampel secara acak dijadikan eksperimen (Lufri, 2005). Peneliti menggunakan sekelompok subjek dari populasi tertentu, selanjutnya dikelompokkan secara acak menjadi beberapa kelompok kelas, yaitu kelompok kelas eksperimen dan kelas kontrol. Kelompok kelas eksperimen disini yaitu pembelajaran dengan menggunakan model Jigsaw dan kelompok kelas kontrol menggunakan metode pembelajaran yang biasa atau belum menggunakn model pembelajaran Jigsaw. Kemudian masing-masing akan diberikan tes akhir.

Populasi penelitian adalah semua siswa kelas VA dan VB SDN 9 Aie Pacah Padang tahun pelajaran 2017/2018. Teknik pengambilan sampel diperoleh dengan cara total sampling, hal ini karena jumlah populasinya sebanyak 39 orang siswa sehingga seluruh siswa dijadikan sampel. Pada pendelitian ini terdapat dua variabel yaitu variabel bebas dan variabel terikat. Variabel bebas penelitian ini adalah model pembelajaran jigsaw, sedang kan variabel terikat penelitian ini adalah hasil belajar siswa. Pelaksanaan penelitian dibagi atas tiga bagian yaitu: persiapan, pelaksanaan, dan penyelesaian.

Pada teknik pengumpulan data dilakukan dengan cara tes. Menurut (Arikunto, 2011) tes adalah alat evaluasi atau instrument dalam upaya pengukuran tingkat kemampuan siswa dalam pembelajaran. Berdasarakan penjelasan tersebut maka peneliti akan melakukan tes dengan cara post-tes. post-tes akan dilakukan di kedua kelas setelah dilakasanakan pembelajaran yang berbeda yakni kelas eksperimen dengan model pembelajaran Jigsaw dan kelas kontrol dengan model pembelajaran konvensional.

\section{HASIL DAN PEMBAHASAN}

Sesuai dengan hasil perhitungan maka hasil yang diperoleh adalah:

Tabel 2. Hasil Validitas Uji Coba Tes

\begin{tabular}{|c|c|c|}
\hline $\begin{array}{c}\text { Koefisien } \\
\text { Validitas }\end{array}$ & Kategori & Nomor Soal \\
\hline $0,800-1,00$ & $\begin{array}{c}\text { Sangat } \\
\text { Tinggi }\end{array}$ & 16 \\
\hline $0,600-0,800$ & Tinggi & $1,5,12,14,20$, \\
& & $27,28,29,30$ \\
\hline $0,400-0,600$ & Cukup & $2,4,6,7,10,11$, \\
& & $17,19,24$, \\
\hline $0,200-0,400$ & Rendah & $3,8,21$ \\
\hline $0,00-0,200$ & Sangat & $9,13,15,18$, \\
& Rendah & $22,23,25,26$ \\
\hline
\end{tabular}

Dilihat pada tabel 2, kriteria validitas soal kriteria sangat tinggi sebanyak 2 buah soal pada nomor 5, 6 Sedangkan validitas pada kriteria tinggi tidak ada. Kemudian pada validitas kriteria cukup 
sebanyak 3 buah soal pada nomor 1. Berdasarkan tabel di atas terlihat bahwa terdapat soal-soal yang tidak valid yaitu pada nomor soal 3, 8, 9, 13, 15, $18,22,23,25$ dan 26. Sedangkan nomor soal 1, 2, $4,5,6,7,10,11,12,14,16,17,19,20,21,24,27$, 28,29 dan 30 adalah soal yang valid.

Tabel 3. Hasil Daya Pembeda Soal

\begin{tabular}{|c|c|c|}
\hline $\begin{array}{c}\text { Daya } \\
\text { Pembeda }\end{array}$ & Kriteria & Nomor Soal \\
\hline $0,00-0,20$ & Jelek (poor) & $\begin{array}{c}8,9,13,15, \\
18,22,23,25,26\end{array}$ \\
\hline $0,21-0,40$ & $\begin{array}{c}\text { Cukup } \\
\text { (satistifactory) }\end{array}$ & 3, \\
\hline $0,41-0,70$ & Baik (good) & $1,2,4,5,6,7$, \\
& & $10,12,14,6$, \\
& & $17,19,28$ \\
\hline $0,71-1,00$ & Baik sekali & $11,20,21,24,27,29,3$ \\
& (excellent) & 0 \\
\hline
\end{tabular}

Berdasarkan tabel 3 kriteria indeks daya pembeda soal, sebanyak 7 butir pada nomor soal berada pada kategori baik sekali 11, 20, 21, 24, 27, 29 dan 30, Pada kategori baik terdapat 12 butir pada nomor soal $1,3,4,5,6,10,12,14,16,17,19$ dan 28 , kemudian 2 butir pada kategori cukup yaitu nomor soal 2 dan 3 , dan 8 butir pada nomor soal $8,9,13,15,18,22,23$, dan 25 masuk kategori jelek.

Tabel 4. Hasil Analisis Indeks Kesukaran

\begin{tabular}{|c|c|c|}
\hline $\begin{array}{c}\text { Indek } \\
\text { Kesukaran } \\
\text { Soal }\end{array}$ & Kriteria & Nomor soal \\
\hline $0,00-0,30$ & Soal Sukar & - \\
\hline & & $1,2,3,4,5,6,7$, \\
& Soal & $8,9,10,11,12,13$, \\
$0,31-0,70$ & Sedang & $14,15,16,17,18$, \\
& & $25,20,21,22,23,24$, \\
& & \\
\hline $0,71-1,00$ & Sukar & \\
\hline
\end{tabular}

Berdasarkan tabel 4 kriteria taraf kesukaran soal pada penelitian ini peneliti mendapatkan dari taraf kesukaran soal yang tergolong sedang untuk semua soal. Uji reliabilitas berdasarkan rumus Kuder Richardson (K-R 20).

Tabel 5. Hasil Reabilitas Uji Coba Soal

\begin{tabular}{|c|c|c|c|}
\hline Sampel & Rata-rata & Reliabilitas & Kriteria \\
\hline 15 & 14,40 & 0.76 & Tinggi \\
\hline
\end{tabular}

Berdasarkan tabel 5 terlihat bahwa hasil uji coba tes diperoleh reliabilitasnya 0.76 maka kriteria reliabilitas soal adalah pada kriteria tinggi

Tabel 6. Hasil Uji Normalitas Kedua Kelas Sampel:

\begin{tabular}{|l|c|c|c|}
\hline \multirow{2}{*}{ Kelompok } & \multicolumn{2}{|c|}{ Uji Lilliefors } & \multirow{2}{*}{ Kesimpulan } \\
\cline { 2 - 3 } & $\mathrm{L}_{\mathrm{o}}$ & $\mathrm{L}_{\text {tabel }}$ & \\
\hline $\begin{array}{l}\text { Posttes Kelas } \\
\text { Kontrol }\end{array}$ & 0,139 & 0,195 & Normal \\
\hline $\begin{array}{l}\text { Postes Kelas } \\
\text { Eksperimen }\end{array}$ & 0,177 & 0,190 & Normal \\
\hline
\end{tabular}

Sesuai dengan penjelasan tabel pada 6 probabilitasnya memenuhi kriteria $\mathrm{L}_{\mathrm{o}}<\mathrm{L}_{\text {Tabel. }}$. Pada kelompok kontrol $\mathrm{L}_{\mathrm{o}}<\mathrm{L}_{\text {Tabel }}(0,139<0,195)$ dan pada post test kelompok eksperimen $\mathrm{L}_{\mathrm{o}}<\mathrm{L}_{\text {Tabel }}$ $(0,177<0,190)$ maka data tersebut berdistribusi normal.

Tabel 7. Hasil Uji Homogenitas Kedua Kelas Sampel

\begin{tabular}{|c|c|c|c|c|c|}
\hline $\begin{array}{c}\text { Kelompok } \\
\text { Sampel }\end{array}$ & $\begin{array}{c}\text { Jumla } \\
\mathrm{h}(\mathrm{N})\end{array}$ & $\begin{array}{c}\text { Taraf } \\
\text { Nyata }\end{array}$ & $\mathrm{F}_{\text {hit }}$ & $\mathrm{F}_{\text {tab }}$ & Keterangan \\
\hline Kelas Kontrol & 19 & 0,05 & \multirow{2}{*}{2.151} & 2,188 & Homogen \\
\hline $\begin{array}{c}\text { Kelas } \\
\text { Eksperimen }\end{array}$ & 20 & 0,05 & 2.15 & \\
\hline
\end{tabular}


Sesuai petunjuk pada tabel 7, kelompok data memiliki homogenitas pada taraf signifikansi 0,05 dengan $\mathrm{dk}=(\mathrm{n}-1)$, karena nilai $\mathrm{F}_{\text {hitung }}<\mathrm{F}_{\text {tabel }}$ $(2.151<2,188)$.

Tabel 8. Hasil Uji Hipotesis

\begin{tabular}{|c|c|c|c|c|}
\hline Variabel & Pengukuran & $\mathrm{t}_{\text {hit }}$ & $\mathrm{t}_{\mathrm{tab}}$ & Keterangan \\
\hline Hasil & Kontrol & \multirow[b]{2}{*}{3,808} & \multirow[b]{2}{*}{2,576} & \multirow[b]{2}{*}{ Signifikan } \\
\hline $\begin{array}{l}\text { Belajar } \\
\text { Bahasa } \\
\text { Indonesia }\end{array}$ & Eksperimen & & & \\
\hline
\end{tabular}

Bedasarkan tabel 8 analisis data diperoleh $t_{\text {hitung }}=2,41$ dan $t_{\text {tabel }}=2,04$ dimana $t_{\text {hitung }}>t_{\text {tabel }}$ berarti $2,41>2,04$. Dengan demikian, dapat disimpulkan bahwa $\mathrm{H}_{1}$ diterima.

Setelah dilakukan analisis data hasil belajar melalui Uji Normalitas, Uji Homogenitas dan Uji Hipotesis maka diperoleh skor maksimum, skor minimum, nilai rata-rata $(\overline{\mathrm{X}})$, varians $\left(\mathrm{S}^{2}\right)$, dan simpangan baku (S).

Tabel 9. Nilai Rata-rata, Simpangan Baku dan Varians Kedua Kelas Sampel

\begin{tabular}{|c|c|c|c|c|}
\hline Sampel & $\mathrm{N}$ & $\overline{\mathrm{X}}$ & $\mathrm{S}$ & $\mathrm{S}^{2}$ \\
\hline $\begin{array}{c}\text { Kelas } \\
\text { Eksperimen }\end{array}$ & 19 & 73,42 & 23,98 & 575,146 \\
\hline $\begin{array}{c}\text { Kelas } \\
\text { Kontrol }\end{array}$ & 20 & 79,00 & 16,35 & 267,3684 \\
\hline
\end{tabular}

Tabel 10. Distribusi Frekuensi Hasil Belajar Bahasa Indonesia pada Kelompok Kontrol

\begin{tabular}{|c|c|c|c|c|}
\hline $\begin{array}{c}\text { Tingkat } \\
\text { Penguasaa } \\
\mathrm{n}\end{array}$ & $\begin{array}{c}\text { Nilai Skala } \\
100\end{array}$ & Klasifikasi & Frekuensi & Persentase \\
\hline $96-100 \%$ & 100 & Sempurna & 5 & 26.3 \\
\hline $86-95 \%$ & 90 & Baik Sekali & 1 & 5.3 \\
\hline $76-85 \%$ & 80 & Baik & 5 & 26.3 \\
\hline $66-75 \%$ & 70 & $\begin{array}{c}\text { Lebih dari } \\
\text { cukup }\end{array}$ & 1 & 5.3 \\
\hline
\end{tabular}

\begin{tabular}{|c|c|c|c|c|}
\hline $56-65 \%$ & 60 & Cukup & 2 & 10.5 \\
\hline $46-55 \%$ & 50 & $\begin{array}{c}\text { Hampir } \\
\text { cukup }\end{array}$ & 2 & 10.5 \\
\hline $36-45 \%$ & 40 & Kurang & 2 & 10.5 \\
\hline $26-35 \%$ & 30 & $\begin{array}{c}\text { Kurang } \\
\text { sekali }\end{array}$ & 0 & 0.0 \\
\hline $16-25 \%$ & 20 & Buruk & 1 & 5.3 \\
\hline $0-15 \%$ & 10 & $\begin{array}{c}\text { Buruk } \\
\text { Sekali }\end{array}$ & 0 & 0.0 \\
\hline & & & 19 & 100 \\
\hline
\end{tabular}

Tabel 10 menunjukkan hasil belajar Bahasa Indonesia post test pada kelompok kontrol siswa kelas V SDN 09 Aie Pacah Padang dari 19 orang sampel dengan 5 orang (26.3\%) pada klasifikasi sempurna, 1 orang (5.3\%) pada klasifikasi baik sekali, 5 orang (26.3\%) pada klasifikasi baik, 1 orang (5.3\%) pada klasifikasi lebih dari cukup, 2 orang (10.5\%) pada klasifikasi cukup, 2 orang (10.5\%) pada klasifikasi hampir cukup, 2 orang (10.5\%) pada klasifikasi kurang dan 1 orang (5.3\%) pada klasifikasi buruk.

Tabel 11. Distribusi Frekuensi Hasil Belajar Bahasa Indonesia pada Kelas Eksperimen

\begin{tabular}{|c|c|c|c|c|}
\hline $\begin{array}{c}\text { Tingkat } \\
\text { Penguasaan }\end{array}$ & $\begin{array}{c}\text { Nilai } \\
\text { Skala } \\
100\end{array}$ & Klasifikasi & $\begin{array}{c}\text { Frekuens } \\
\mathrm{i}\end{array}$ & Persentase \\
\hline $96-100 \%$ & 100 & Sempurna & 3 & 15.0 \\
\hline $86-95 \%$ & 90 & Baik Sekali & 4 & 20.0 \\
\hline $76-85 \%$ & 80 & Baik & 7 & 35.0 \\
\hline $66-75 \%$ & 70 & $\begin{array}{l}\text { Lebih dari } \\
\text { cukup }\end{array}$ & 0 & 0.0 \\
\hline $56-65 \%$ & 60 & Cukup & 4 & 20.0 \\
\hline $46-55 \%$ & 50 & $\begin{array}{l}\text { Hampir } \\
\text { cukup }\end{array}$ & 2 & 10.0 \\
\hline $36-45 \%$ & 40 & Kurang & 0 & 0.0 \\
\hline $26-35 \%$ & 30 & $\begin{array}{l}\text { Kurang } \\
\text { sekali }\end{array}$ & 0 & 0.0 \\
\hline $16-25 \%$ & 20 & Buruk & 0 & 0.0 \\
\hline \multirow[t]{2}{*}{$0-15 \%$} & 10 & $\begin{array}{l}\text { Buruk } \\
\text { Sekali }\end{array}$ & 0 & 0.0 \\
\hline & & & 20 & 100 \\
\hline
\end{tabular}

Tabel 11 menunjukkan distribusi frekuensi hasil belajar Bahasa Indonesia pada kelompok 
eksperimen siswa kelas V SDN 9 Aie Pacah Padang dari 20 orang sampel dengan 3 orang (15\%) pada klasifikasi sempurna, 4 orang (20\%) pada klasifikasi baik sekali, 7 orang $(35 \%)$ pada klasifikasi baik, 4 orang (20\%) pada klasifikasi cukup dan 2 orang (10\%) pada klasifikasi hampir cukup.

Setelah dilakukan proses penelitian nilai rata-rata pada kelas VA adalah 73.42 dengan standar deviasi $\pm 23,98$, nilai minimum 20 , dan nilai maksimum 100, Sedangkan nilai rata-rata pada VB adalah 79,00 dengan standar deviasi \pm 16,35, nilai minimum 50 dan nilai maksimum 100. Berdasarkan analisis data diperoleh $\mathrm{t}_{\text {hitung }}=11,139$ dan $t_{\text {tabel }}=3,808$ yaitu $t_{\text {hitung }}>t_{\text {tabel }}$ maka hipotesis diterima.

\section{SIMPULAN}

Dalam peningkatkan mutu pendidikan maka langkah yang dilakukan guru adalah memperbaiki pembelajarannya atau menyiasati agar kegiatan pembelajaran yang dilakunya berjalan dengan efisien, efektif, dan optimal. Sehingga kreatifitas yang tinggi dan inovasi guru sangat diperlukan dalam hal ini. Salah satu yang penelitan lakukan di SD 9 Aie Pacah adalah dengan melakukan penelitan eksperimen untuk mengadaptasikan kegiatan pembelajaran.

Sesuai denagn hasil yang diperoleh pada penelitian terdapat pengaruh model pembelajaran Jigsaw terhadap hasil belajar Bahasa Indonesia siswa kelas V di Sekolah Dasar Negeri 9 Aie Pacah Padang, melalui uji t pada taraf 0,05 dengan hasil $t_{\text {hitung }}=11,139$ dan $t_{\text {tabel }}=3,808$ yaitu $t_{\text {hitung }}>$ $t_{\text {tabel }}$ hipotesis diterima, maka terdapat pengaruh yang sangat signifikan terhadap hasi belajar bahasa indoneisa siswa di kelas VB pada semester II di Sekolah Dasar Negeri 9 Aie Pacah Padang pada tahun ajaran 2018/2019.

Setelah kita melihat hasil penelitian eksperimen ini, maka peneliti mengajukan saransaran. Pertama, Saya menyarankan kepada guru SDN 9 Aie Pacah Padang sering melakukan penelitian terhadap kebutuhan peserta didik akan pelajaran dan kemudian mengadaptasikannya terhadap keadaan proses pembelajaran, seperti menggunakan model pembelajaran jigsaw dan sebagainya. Tujuannya yaitu agar proses pembelajaran efektif, efisien, dan optimal. Kedua, disarankan kepada siswa kelas V SDN 9 Aie Pacah Padang untuk lebih banyak berlatih sesering mungkin dalam hal membaca dan sebagainya supaya menjadi generasi yang berprestasi.

\section{DAFTAR PUSTAKA}

Arikunto, S. (2011). Dasar-dasar Evaluasi Pendidikan. Jakarta: Buku Aksara.

Bessho, S. ichiro, Noguchi, H., Kawamura, A., Tanaka, R., \& Ushijima, K. (2019). Evaluating remedial education in elementary schools: Administrative data from a municipality in Japan. Japan and the World Economy, 50(May), 36-46. https://doi.org/10.1016/j.japwor.2019.04.003

Fahyuni, E. F., \& Fauji, I. (2017). Pengembangan Komik Akidah Akhlak Untuk Meningkatkan Minat Baca dan Prestasi Belajar Siswa di Sekolah Dasar. Halaqa: Islamic Education Journal, $\quad 1(1), \quad 17$. https://doi.org/10.21070/halaqa.v1i1.817

Kichi Hermansyah, A., \& Hasanah, M. (2017). Pembelajaran Membaca Cepat Di Sekolah 
680 Pengaruh Model Pembelajaran Jigsaw Terhadap Hasil Belajar Bahasa Indonesia di Sekolah DasarDiki Heriwan, Taufina

DOI: 10.31004/basicedu.v4i3.416

Dasar. 578-583.

Lubis, A. B., Miaz, Y., Taufina, \& Desyandri. (2019). Pengaruh Model Everyone Is a Teacher Here Terhadap Aktivitas Dan Hasil Belajar Ips Siswa Sd. Jurnal Basicedu, 3(2), 725-735.

https://doi.org/https://doi.org/10.31004/basic edu.v3i2.61

Lufri. (2005). Buku Ajar Metodologi Penelitian. In Padang: UNP,.

Madhavi, M., \& Murthy, G. V. (2020). Role of certifications in improving the quality of Education in Outcome Based Education. 33(January), 582-584.

Muhammadi, M., Taufina, T., \& Chandra, C. (2018). Literasi Membaca Untuk Memantapkan Nilai Sosial Siswa SD. https://doi.org/10.21831/ltr.v17i2.16830

Pane, M. M., \& Patriana, R. (2016). The Significance of Environmental Contents in Character Education for Quality of Life. Procedia - Social and Behavioral Sciences, 222, 244-252. https://doi.org/10.1016/j.sbspro.2016.05.153

Pina, A., \& Rubio, G. (2017). Using educational robotics with primary level students (6-12 years old) in different scholar scenarios: Learned lessons. CSEDU 2017 - Proceedings of the 9th International Conference on Computer Supported Education, 1(Csedu), 196-208.

https://doi.org/10.5220/0006381501960208

Putra, A. A., Hardianti, T., Syahwin, \& Fauzi. (2018). Pengaruh Model Pembelajaran Jigsaw Terhadap Hasil the Influence of Jigsaw Learning Model on Learning. Journal of Physics and Science Learning, 02(1), 916.

Sukma, E., Mahyudin, R., Rahmatina, R., \& Suriani, A. (2019). Problems in Oral Language Teaching in Primary School. 301(Icla), 379-383. https://doi.org/10.2991/icla-18.2019.63
Taufina. (2016). Membangun Hubungan Interpersonal Positif Melalui Kesepadanan Kalimat Tanya dan Unsur Nonverbal di Kelas I Sekolah Dasar. 154-169.

Taufina, Chandra, \& Kharisma, A. (2019). Technology integration in thematic learning to welcome the era of the industrial revolution 4.0 in elementary schools. Proceeding Internasional Seminar of Primary Education, 2, 10-19. https://doi.org/https://doi.org/10.24114/esjpg sd.v9i1.14297

Winarto, Y. J. (2020). Efforts to Increase the Pedagogics of Teachers in Making IT-Based Learning Media in the 4.0 Era. 387(Icei), 113-116. https://doi.org/10.2991/icei19.2019 .27 